\title{
Morin promotes prostate cancer cells chemosensitivity to paclitaxel through miR-155/GATA3 axis
}

\author{
Bin Li ${ }^{1}$, Xunbo Jin ${ }^{1}$, Huilin Meng ${ }^{1}$, Bo Hu${ }^{1}$, Tao Zhang ${ }^{1}$, Jiang $\mathbf{Y u}^{1}$, Shaoan Chen ${ }^{1}$, \\ Xudong Guo ${ }^{1}$, Weiguo Wang ${ }^{2}$, Wei Jiang ${ }^{3}$ and Jin Wang ${ }^{4,5}$ \\ ${ }^{1}$ Minimally Invasive Urology Center, Shandong Provincial Hospital Affiliated to Shandong University, Jinan 250021, Shandong, \\ China \\ ${ }^{2}$ Department of Urology, Jining No.1 People's Hospital, Jining 272011, Shandong, China \\ ${ }^{3}$ Department of Urology, Dongying People's Hospital, Dongying 257091, Shandong, China \\ ${ }^{4}$ Department of Urology, Shandong Provincial Qianfoshan Hospital Affiliated to Shandong University, Jinan 250014, Shandong, \\ China \\ ${ }^{5}$ School of Basic Medical Sciences, Shandong University, Jinan 250012, Shandong, China \\ Correspondence to: Jin Wang, email: wjinsdu@163.com \\ Keywords: prostate cancer, morin, paclitaxel-resistance, microRNA (miR)-155, GATA binding protein 3 (GATA3) \\ Received: February 28, $2017 \quad$ Accepted: April 21, $2017 \quad$ Published: May 24, 2017 \\ Copyright: $\mathrm{Li}$ et al. This is an open-access article distributed under the terms of the Creative Commons Attribution License \\ 3.0 (CC BY 3.0), which permits unrestricted use, distribution, and reproduction in any medium, provided the original author and \\ source are credited.
}

\section{ABSTRACT}

Paclitaxel is a first-line microtubule-stabilizing drug in treating prostate cancer. However, most patients develop resistance and experience relapse. Morin $(3,5,7,20,40$-pentahydroxyflavone) is an anti-tumor flavonoid in a numerous types of cancer cells including breast, ovarian and lung cancers. We therefore researched the effects of morin as an adjuvant to paclitaxel in in treating DU145 and PC-3 cells in vitro and DU145 derived prostate cancers in nude mice models. The chemosensitivities of these cells to the treatments of morin and paclitaxel were tested through viability assays utilizing cell counting kit 8 ( CCK-8) and apoptosis assays through flow cytometry analyses. MicroRNA (miRNA) microarray was employed to determine the changes in miRNA profile of morin treated DU145 cells. The results from microarrays were further certified by quantitative real-time reverse transcription-PCR (qRT-PCR). The underlying targets of miR-155 were verified using luciferase assays followed by Western blot assays. In the results, morin was capable of repressing the cell viabilities in the paclitaxel-treated cells. MiR-155might be an effective target that can be downregulated in morin-treated cells. We also discovered that GATA binding protein 3 (GATA3) was directly repressed by miR-155, and the treatment of morin reversed the expression of GATA3. In conclusion, morin might be a potential adjuvant of paclitaxel in treating prostate cancer through regulating miR-155/GATA3 axis.

\section{INTRODUCTION}

Paclitaxel, an alkaloid originally discovered in pacific yew tree, has long been used as a first-line treatment of prostate cancer. The antitumor effect of paclitaxel has been attributed to mitotic arrest, in which microtubule is stabilized to prevent chromosome segregation and cytokinesis [1]. However, most patients rapidly develop resistance to paclitaxel and experience relapse [2].
Therefore, it is important to develop new methods to conquer the drug resistance. By now, it is clear that alterations in the expressions of microtubule subtypes and the subsequent cell signaling could influence the affinity of the drug and the downstream response of the cell [3]. Hence, combination therapy might be efficient to prevent drug resistance through altering the microtubule expressions.

MicroRNAs (miRNAs) are small non-coding RNAs (19-25 nt) that modulate the translation of mRNAs 
through binding to its 3'-untranslated region (UTR) [4]. Studies have shown that each tumor type has a distinct miRNA profile that correlates to their relevant subtypes, patient survivals and treatment responses in different cancers [5]. This provides a convenient method to understand the efficacies of drugs on tumor cells and their molecular mechanisms. MiR-155 is a multi-functional miRNA that participates in innate and acquired immune responses and hematopoiesis [6, 7]. MiR-155 dysregulation has been reported in numerous malignant tumors including leukemia, breast and lung cancers $[8,9]$. Recent data has shown that miR-155 can be markedly overexpressed in prostate cancer cells [10, 11]. Researches have demonstrated that miR-155 could promote cell proliferation, enhance tumor growth and inhibit apoptosis through suppressing the expression of proteins like TP53INP1, VHL, PIK3RI [12-14]. Nevertheless, the understandings of the mechanisms of miR-155 in promoting the progression of cancers, and researches investigating the effects of miR-155 to prostate cancer are limited.

Morin (3,5,7,20,40-pentahydroxyflavone) is a flavonoid isolated from figs and other members of Moraceae family. In recent studies, morin has exhibited effects on regulating cell survival and proliferation-related genes, promoting apoptosis and chemo-sensitivity in multiple cancer cell lines [15-17]. Researches have shown that morin can upregulate intrinsic apoptosis pathways $[15,17,18]$. In breast cancer cells, $50 \mu \mathrm{M}$ of morin was effective in reverting their malignant phenotypes [19]. Therefore, we hypothesized that $50 \mu \mathrm{M}$ of morin can be an effective adjuvant of paclitaxel in delaying the development of drug resistance. Experiments in vivo and in vitro showed that morin increased the chemo-sensitivity to paclitaxel. The results of miRNA microarray revealed that miR-155 was significantly repressed by treatment of morin. GATA binding protein 3(GATA3) was significantly downregulated by miR-155.

\section{RESULTS}

\section{Morin promotes chemo-sensitivity of prostate cancer cells to paclitaxel}

DU145 and PC-3 cell lines are standard models that have been widely used in studying prostate cancers. Hence they are more universal comparing to cell lines derived from patients. To evaluate the cytotoxicity of morin as an adjuvant to paclitaxel, we firstly evaluated the viabilities of DU145 and PC-3 cells in the environment of morin and paclitaxel using CCK-8 kit. In the experiments, cells were cultured in the medium containing $50 \mu \mathrm{M}$ morin dissolved in DMSO and a gradient of paclitaxel (0-100 $\mathrm{nM}$ ) for $48 \mathrm{~h}$ (Figure 1) and $72 \mathrm{~h}$ (Supplementary Figure 1). The same amount of DMSO was treated in control groups. The cytotoxicity of $50 \mu \mathrm{M}$ morin alone was limited within $48 \mathrm{~h}$ of treatment (Figure 1A and 1B; all $\mathrm{P}<$ $0.01)$. The cell viabilities of both cell lines were influenced only after $72 \mathrm{~h}$ treatment comparing with the DMSO control (Supplementary Figure $1 \mathrm{~A}$ and $1 \mathrm{~B}$; all $\mathrm{P}<0.01$ ). However, when paclitaxel was treated at the same time, the viabilities of morin-treated groups in both of the cell lines were significantly lower than DMSO control groups in both the time points of $48 \mathrm{~h}$ and $72 \mathrm{~h}$ (Figure $1 \mathrm{~A}$ and 1B; Supplementary Figure $1 \mathrm{~A}$ and $1 \mathrm{~B}$; all $\mathrm{P}<0.01)$. These results were then verified by measuring relative apoptosis rates using flow cytometry in PC-3 and DU145 cell lines, in which cells were treated with $50 \mu \mathrm{M}$ morin and 50 $\mathrm{nM}$ paclitaxel for $48 \mathrm{~h}$. Similar to the results in viability assay, morin led to significant increase in cell apoptosis compared with DMSO treatment in both of the cell lines (Figure 1C and 1D; both $\mathrm{P}<0.01$ ).

\section{Morin promotes chemo-sensitivity of prostate cancer cells to paclitaxel in vivo}

We investigated the inhibitory function of morin as an adjuvant to paclitaxel in treating DU145 derived prostate cancer in nude mice models, in which nude mice were divided into paclitaxel treated, morin and paclitaxel treated and DMSO control groups (4 nude mice for each group at indicated time point). DU145 cells were injected into both sides of posterior flank of nude mice. Paclitaxel $(50 \mu \mathrm{g} / \mathrm{kg})$ and morin $(50 \mathrm{mg} / \mathrm{kg})$ were injected by tail vein injection every day for 15 days. Since the day of injection, the tumor sizes were determined every two days, and tumors were excised and weighed after 20 days (Figure 2A-2C). Both the data of tumor size and weight indicated that morin significantly promoted the anti-tumor function of paclitaxel during the process of prostate cancer development in vivo.

\section{Morin inhibits miR-155 expression in prostate cancer cells}

The miRNA profiles of morin and DMSO treated DU145 cells was analyzed to understand how prostate cancer cells were inhibited by morin. A total of 39 microRNAs were found to be altered in morin treated cells, with the most significant one being miR-155 (Figure 3A). Then we assessed the effect of morin on the intracellular concentrations of miR-155 in DU145 and PC-3 cell by qRT-PCR. The results revealed that the transcription of miR-155 was both reduced in morintreated cells compared with control cells (Figure 3B, both $\mathrm{P}<0.01)$.

\section{MiR-155 silencing promoted the chemosensitivities to paclitaxel}

The function miR-155 was silenced in DU145 and PC-3 cells to understand its functions in paclitaxel 
treatment. Firstly, we silenced miR-155 by transfecting anti-miR-155 into DU145 and PC-3 cells. Anti-miR-NC was transfected in the control group. The transfected cells were incubated with paclitaxel (0-100 $\mathrm{nM})$ for $24 \mathrm{~h}$, and CCK-8 kit was subsequently employed to determine the viabilities of these cells. In both cell lines, the viability of miR-155 silenced cells was lower than the control groups (Figure 4A and 4B, all $\mathrm{P}<0.01$ ). Apoptosis assays showed that miR-155 silenced cells exhibited elevated percentages of apoptosis cells compared with control cells (Figure 4C and 4D, both $\mathrm{P}<0.01$ ).

\section{Overexpression of miR-155 reverses the effects of morin on tumor cells}

To understand if miR-155 is directly regulated by morin when it acts as an adjuvant to paclitaxel, miR155 was overexpressed in DU145 and PC-3 cells. To

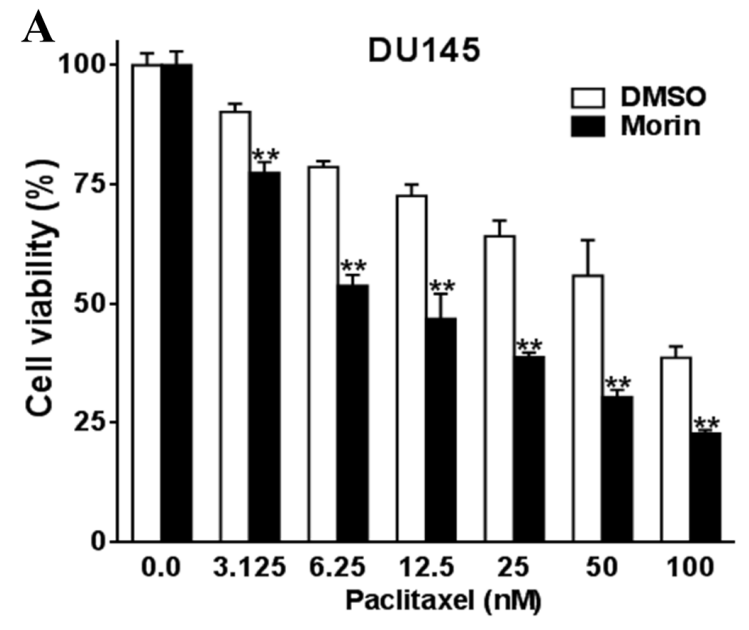

C

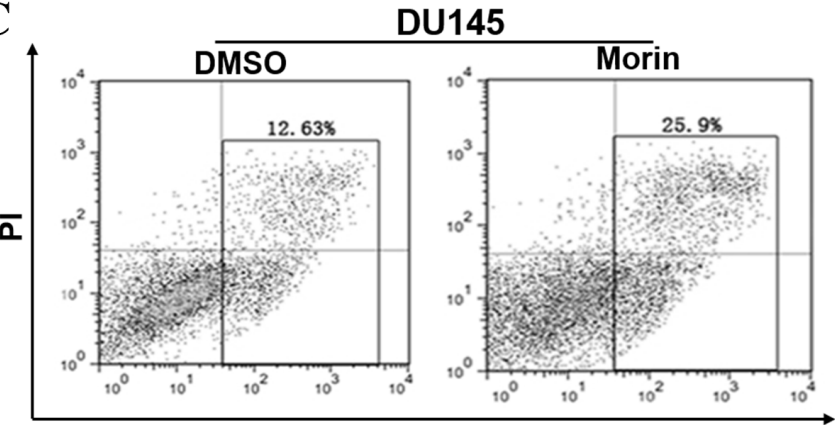

Annexin V-FITC

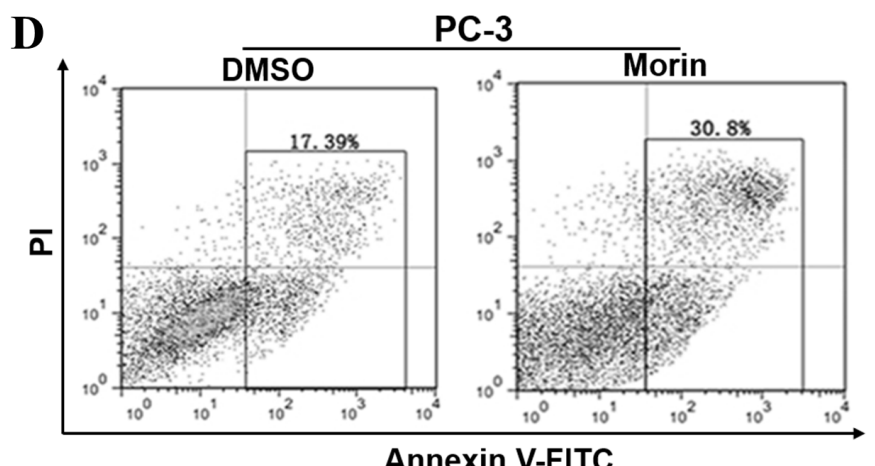

B
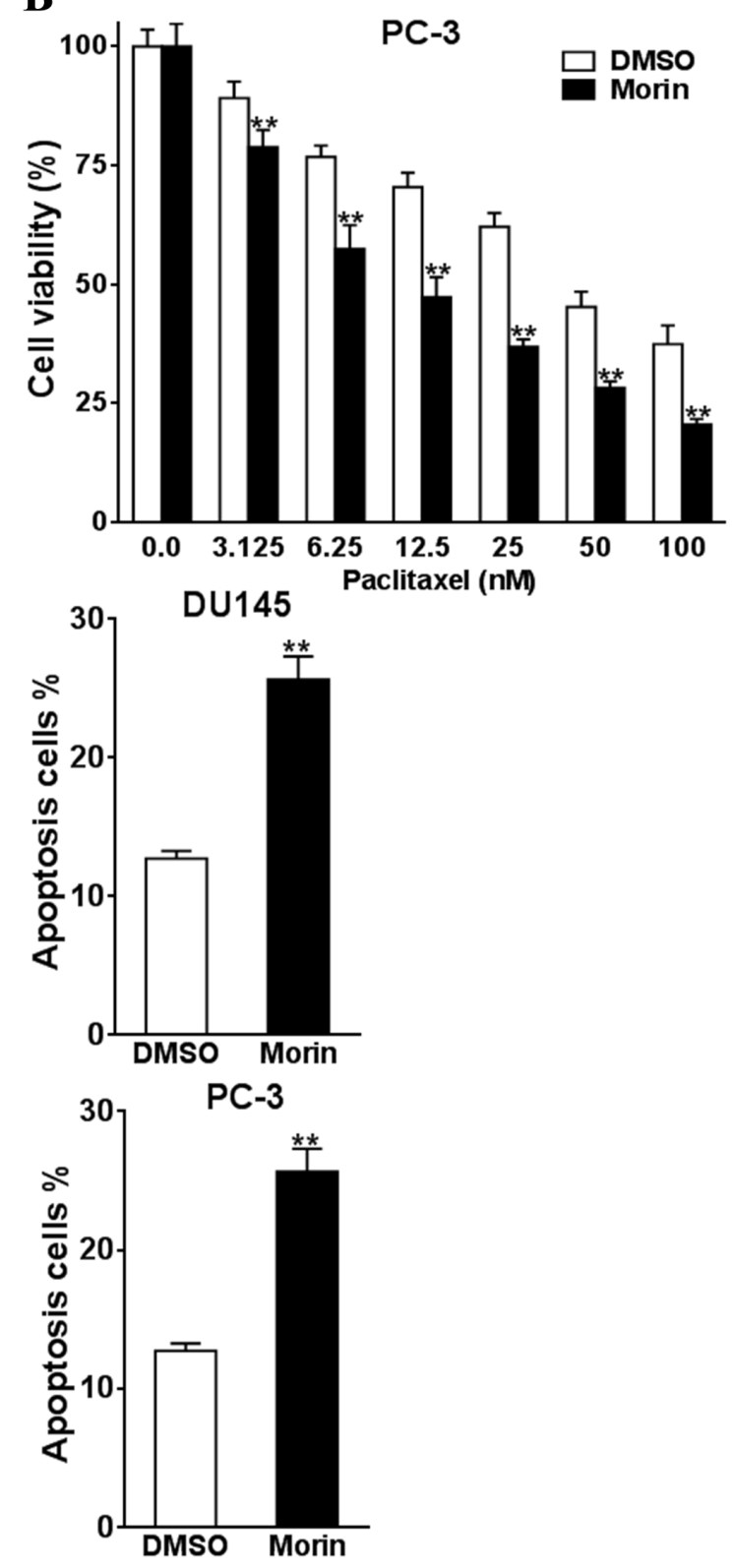

Figure 1: Morin promotes prostate cancer cells chemosensitivity to paclitaxel. (A, B) The cell viabilities of DU145 and PC-3 cells to morin $(50 \mu \mathrm{M})$ and paclitaxel $(0-100 \mathrm{nM})$ were evaluated using CCK-8 assay after $48 \mathrm{~h}$ of incubation. (C, D) The apoptosis levels of DU145 and PC-3 cells to the treatment of morin $(50 \mu \mathrm{M})$ and paclitaxel $(50 \mathrm{nM})$ were determined by flow cytometry. All of the experiments were triplicated and data were shown in mean $\pm \mathrm{SD}$, and the data were shown as the percentage compared to the DMSO control. Student $\mathrm{T}$ tests were used to verify the significance of differences between two groups. ${ }^{* *} \mathrm{p}<0.01$, indicate significant difference compared to DMSO control. 
do this, miR-155 mimics were transfected to increase the intracellular level of miR-155, and miR-NC were transfected as control. Transfected cells were then incubated with or without $50 \mu \mathrm{M}$ morin and $0-100 \mathrm{nM}$ paclitaxel at $37^{\circ} \mathrm{C}$. After $48 \mathrm{~h}$ of treatments, the viabilities of cells treated with morin were notably decreased when comparing with the control cells treated with DMSO in both cell lines (Figure 5A and 5B; all $\mathrm{P}<0.01$ ). However, the transfection of miR-155 mimics rallied the degree of apoptosis to the level similar to the control group (Figure 5A and 5B; all $\mathrm{P}<0.01$ ). These results were consistent with them from apoptosis assays, which were performed on cells pre-treated with $50 \mathrm{nM}$ paclitaxel. In the experiments, the transfection of miR-155 in morin treated cells reversed the degree of apoptosis to a lower level (Figure 5C and 5D, all $\mathrm{P}<0.01$ ).

\section{GATA3 was a downstream effector of miR-155}

We performed in silico analyses to determine the underlying targets of miR-155 through Targetscan (http:// www.targetscan.org/vert_71/) and miRWalk (http://zmf. umm.uni-heidelberg.de/apps/zmf/mirwalk2/, Figure 6A). Among the 5348 genes evaluated, we found that 3 genes, PAK2, XRN1 and GATA3 contained most potential as targets of miR-155 (Figures 6A and 6B). The transcription of these proteins in miR-155 mimic transfected DU145 cells and control cells were then analyzed through qRTPCR. The expressions of all of the three proteins were suppressed in different degree. However, the suppression effect of miR-155 mimic to PAK2 and XRN1 were limited comparing to its effects to GATA3. (Figure 6B; $\mathrm{P}<0.01$ ). To understand if GATA3 is directly regulated by miR-
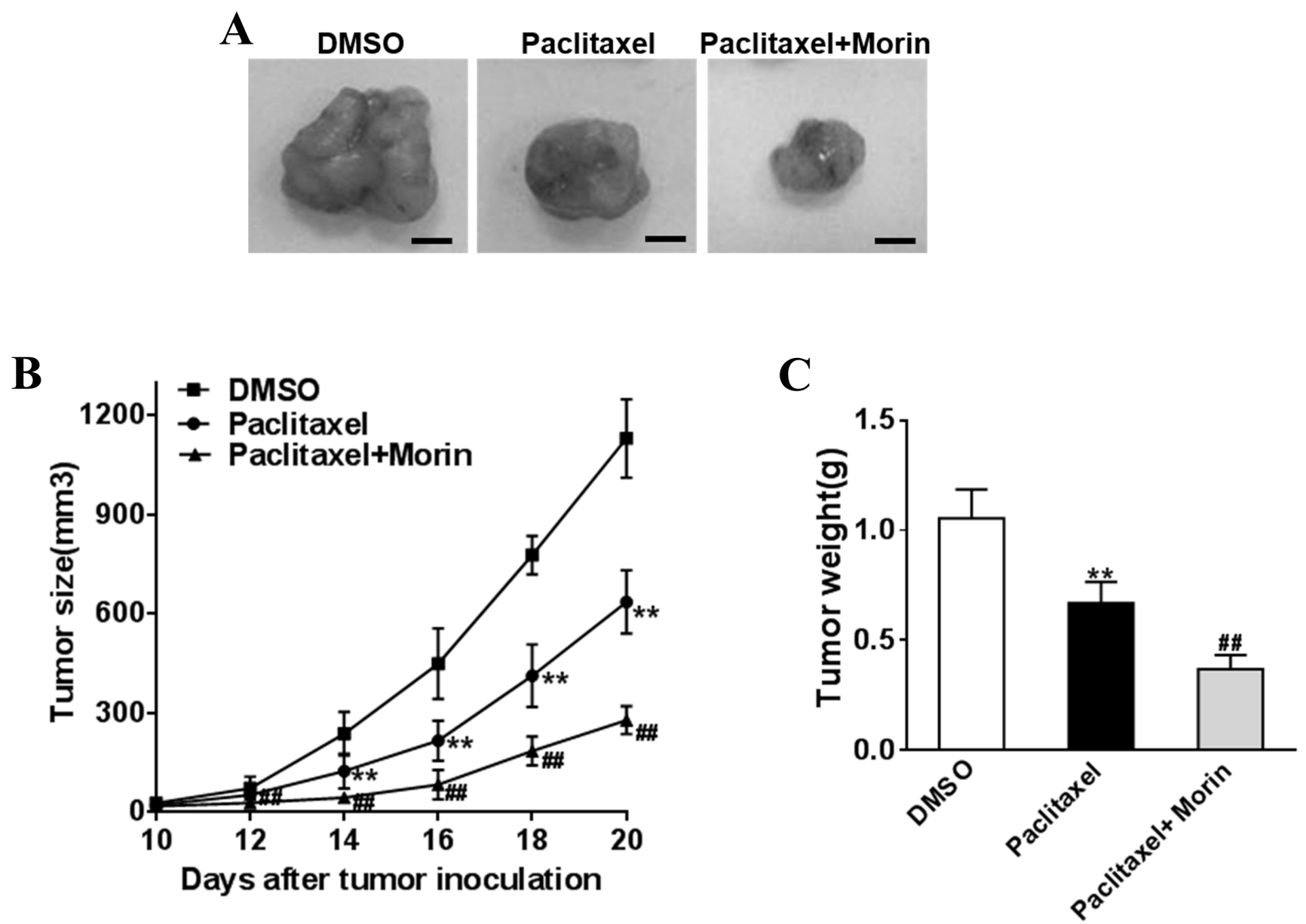

Figure 2: Morin enhances the sensibility of prostate cancer cells to paclitaxel in vivo. The DU145 cells $\left(5 \times 10^{6}\right)$ were suspended in serum-free 1640 medium $(100 \mu \mathrm{L})$ and were subcutaneously injected into each side of posterior flank of the nude mice $(\mathrm{n}=4$ for each group at indicated time point), then paclitaxel $(50 \mathrm{mg} / \mathrm{kg})$ and morin $(50 \mathrm{mg} / \mathrm{kg})$ was added or not by tail vein injection. (A-C) Tumors were measured every two days since they were apparently seen and the volumes were calculated using the following formula: volume $=$ $0.5 \times$ Length $\times$ Width $^{2}$. Tumors were excised and weighed after 20 days with representative pictures of tumors shown $($ Bar $=10 \mathrm{~mm})$. All of the experiments were triplicated and data were shown in mean \pm SD. Student $T$ tests were used to verify the significance of differences between two groups. One or two-way ANOVA analyses was employed for analyzing statistical differences between multiple groups. ** $\mathrm{p}<0.01$, indicate significant difference compared to DMSO group. \#\# $\mathrm{p}<0.01$, indicate significant difference compared to Paclitaxel group. 
155 , the 3 '-UTR of GATA3 was mutated to a sequence that cannot complement miR-155, and Luciferase reporter assays were employed in DU145 cell lines transfected with miR-155 mimics or miR-NC (Figure 6C). We observed that the luciferase activities of wild type GATA3 3'-UTR, but not mutated GATA3 3'-UTR, were notably suppressed in cells with enhanced miR-155 mimics (Figure 6D, P < 0.01). In spite of this, the expression of GATA-3 in these cells were analyzed by Western blotting, in which miR155 mimics decreased the GATA3 expression level in both cell lines in comparison to the control group (Figure 6E).

\section{Morin assisted the antitumor activity of paclitaxel through miR-155/GATA3 axis}

We then evaluated the role of GATA3 in prostate cancer and if it can be regulated by the treatments of morin and paclitaxel. Firstly, the expressions of GATA3 were significantly decreased in prostate cancer tissues (Supplementary Figure 3, $\mathrm{P}<0.01$ ), and the overexpression of GATA3 has been demonstrated to increase the chemosensitivity of DU145 and PC-3 cells to paclitaxel (Supplementary Figure 4, $\mathrm{P}<0.01$ ). We subsequently evaluated the influences of morin and paclitaxel on the expressions of GATA3 in DU145 and PC-3 cell lines. The treatment of paclitaxel or morin alone elevated the expression of GATA3, and morin enhanced the effects of paclitaxel (Supplementary Figure 2, Figure 6F). The next step was to evaluate how morin regulated the expression of miR-155. The cellular level of GATA3 in morin treated miR-155 mimic transfected or control DU145 and PC-3 cells were compared through western blotting, in which the elevated expressions of GATA3 under the treatment of morin were inhibited by miR-155 mimics. We further

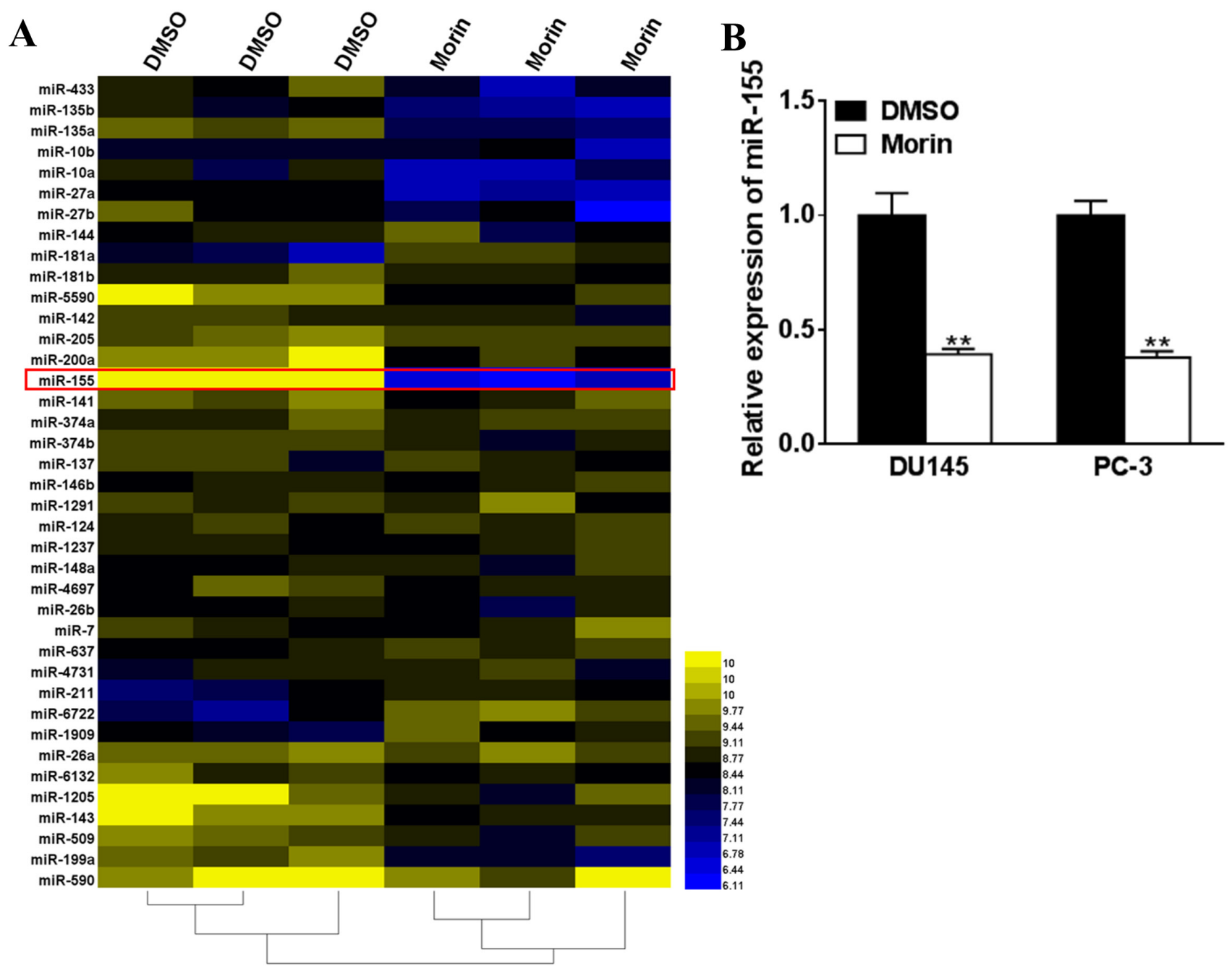

Figure 3: Morin inhibites miR-155 expression in prostate cancer cells. (A) Morin (50 $\mu \mathrm{M})$ or DMSO were added into the medium of DU145 cells, and after $24 \mathrm{~h}$ of incubation, the levels of miRNAs were checked by microarray. (B) DU145 cells were incubated with $50 \mu \mathrm{M}$ morin or DMSO, and after $24 \mathrm{~h}$, the intracellular concentrations of miRNAs were checked by qRT-PCR. All of the experiments were triplicated and data were shown in mean \pm SD. Student $T$ tests were used to verify the significance of differences between two groups. ** $\mathrm{p}<0.01$, indicate significant difference compared to DMSO group. 
demonstrated that the relative expression levels of all of the downstream modulators of GATA3 including ZEB2, TGFB1 and MDM2 were inhibited (Supplementary Figure $5, \mathrm{p}<0.01)$. Hence, it can be said that there might be a miR-155/GATA3 axis involved in the treatment of morin.

\section{DISCUSSION}

Prostate cancer is one of the leading causes of cancer death in male worldwide. Though it is curable in its early stage, the median survival in man with advanced metastatic castration-resistant prostate cancer is less than 2 years [20]. Paclitaxel is the only Food and Drug Administration (FDA) approved chemotherapy that is effective in extending the overall survival of prostate cancer patients [21]. This can be ascribed to the fact that tumors easily acquire resistance to paclitaxel and its derivatives (docetaxel and cabazitaxel) even with the assistance of various adjuvants [21-23]. Recent study has shown that prostate cancer even becomes more aggressive

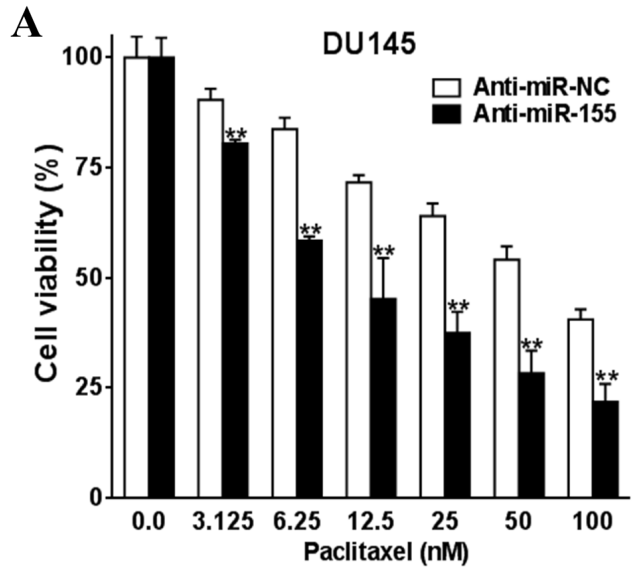

C

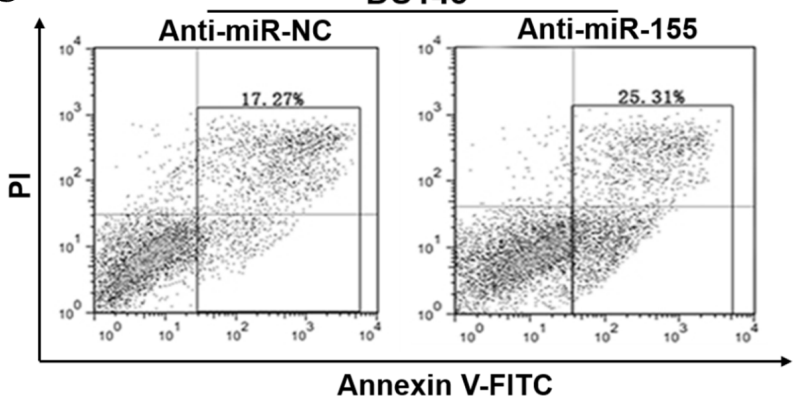

Annexin V-FITC

D

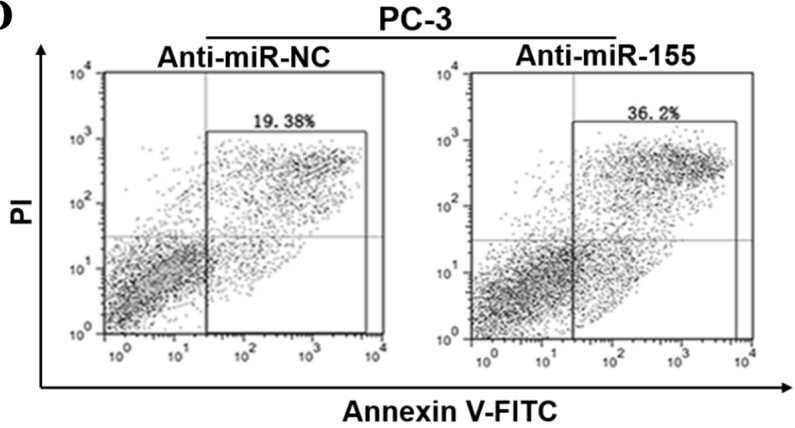

B
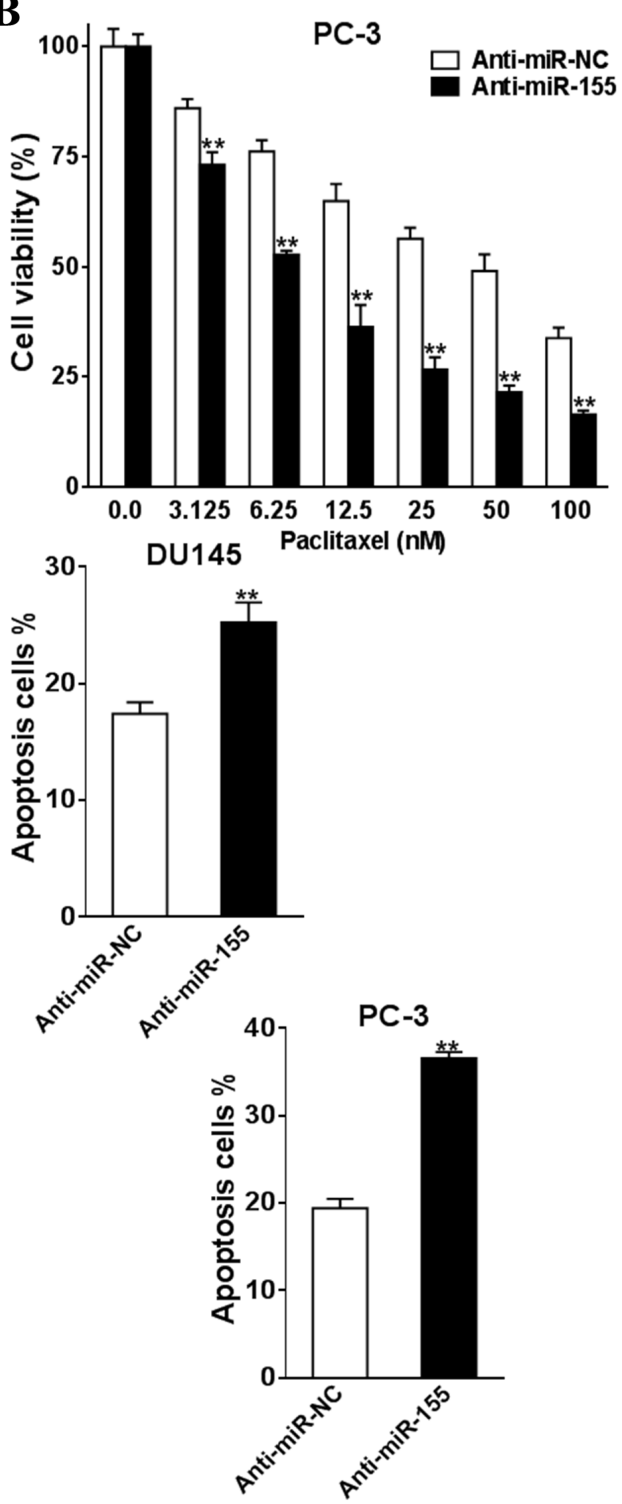

Figure 4: Silence of miR-155 promotes prostate cancer cells chemosensitivity to paclitaxel. Anti-miR-155 inhibitor (AntimiR-155) or control anti-sense RNA (Anti-miR-NC) was transfected into DU145 and PC-3 cells, and were treated with paclitaxel (0-100 nM). After 48 h, CCK-8 assay was used to detected cell viability. (A, B) Anti-miR-155, or Anti-miR-NC were transfected into DU145 and PC-3 cells and were treated with $50 \mathrm{nM}$ paclitaxel. Cell apoptosis was analyzed by flow cytometry as described (C, D). All of the experiments were triplicated and data were shown in mean $\pm \mathrm{SD}$, and the data were shown as the percentage compared to the DMSO+AntimiR-NC control. Student T tests were used to verify the significance of differences between two groups. $* *$ p $<0.01$, indicate significant difference compared to the DMSO +Anti-miR-NC control. 
and invasive when it acquires paclitaxel resistance [24]. Hence it is crucial to develop new adjuvants to overcome the drug resistance in prostate cancer. In the present study, we demonstrate that morin may increase the chemosensitivity of prostate cancer cells to paclitaxel treatment through modulating the expression of miR-155. We also demonstrate that GATA3 may be an important protein involved in the functions of miR-155 in tumor progression.

Morin is a flavonoid isolated from plants of Moraceae family, and contains two aromatic rings linked by an oxygen-containing heterocycle [25]. The anti- tumor effects of morin are widely discovered in a variety of cancers especially in breast cancer and leukemia [15, 18, 26-28]. It has been shown that morin is capable of inhibiting the proliferation and promoting the apoptosis in prostate cancer cell line LNCaP [29, 30], which is consistent with our results that morin repressed the cell viability and enhanced apoptosis of both PC-3 and DU145 cell lines under the treatment of paclitaxel.

Studies have demonstrated that morin induces apoptosis in cancer cell lines through intrinsic apoptosis pathways [17, 18, 26, 27]. The decreased mitochondria
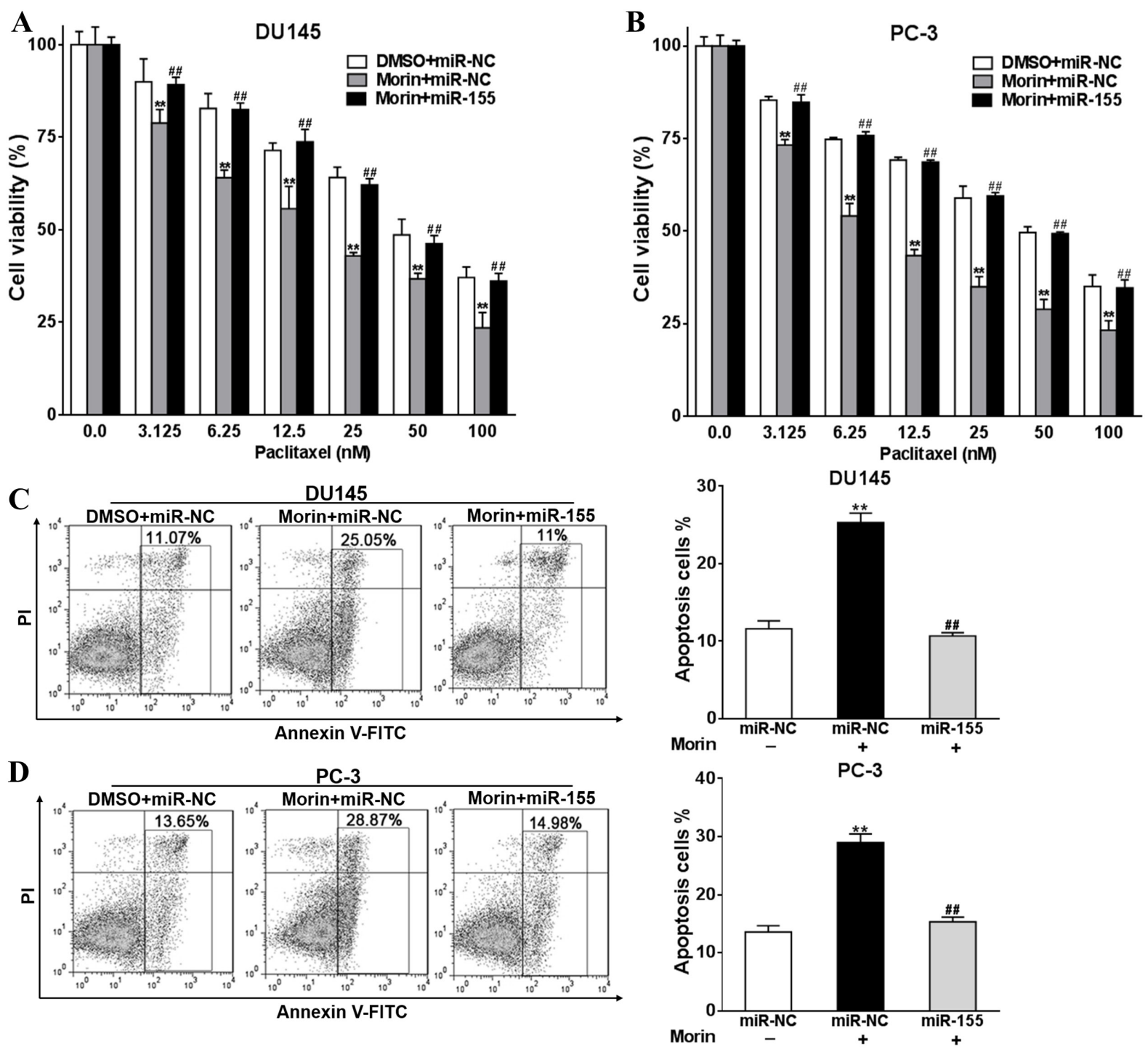

Figure 5: Overexpression of miR-155 reverses the roles of morin in promoting prostate cancer cells sensitivity to paclitaxel. (A, B) DU145 or PC-3 cells were transfected with miR-155 mimics, or control miR-NC, and were treated with $50 \mu \mathrm{M}$ morin or DMSO and $0,3.125,6.25,12.5,25,50,100 \mathrm{nM}$ paclitaxel. After $48 \mathrm{~h}, \mathrm{CCK}-8$ assay was used to detected cell viability. (C, D) DU145 or PC-3 cells were transfected with miR-155 mimics, or control miR-NC, and were treated with $50 \mu \mathrm{M}$ morin or DMSO and $50 \mathrm{nM}$ paclitaxel. After $48 \mathrm{~h}$, cell apoptosis was analyzed by flow cytometry as described. All of the experiments were triplicated and data were shown in mean $\pm \mathrm{SD}$, and the data were shown as the percentage compared to the DMSO+miR-NC control. Student $\mathrm{T}$ tests were used to verify the significance of differences between two groups. One or two-way ANOVA analyses was employed for analyzing statistical differences between multiple groups. ${ }^{* *} \mathrm{p}<0.01$, indicate significant difference compared to DMSO+miR-NC control. \#\# $\mathrm{p}<0.01$, indicate significant difference compared to Morin + miR-NC group. 
potential, the increased expression of caspase-3 and -9, p21 and Bad proteins and the decreased expression of Bcl-xL and STAT3 proteins were widely discovered [17, $18,26]$. Yet, mechanisms underlying the regulation of morin on cell viabilities and apoptosis remain unclear. In this research, we found 39 microRNAs that were dysregulated after the treatment of morin including miR-143, miR-146b, and miR-155. The downregulation of miR-143 and miR-146b has been shown in all types of prostate tumors, which is consistent with our results [31]. However, the inhibitory effects of morin to these two microRNAs were not as effective as miR-155 in our study. The suppression of miR-155 was also discovered the study of the influence of several isoflavones from soy on prostate cancer cell lines, where miR-155, miR208b, miR-211, miR-376a and miR-411 were found to be downregulated by the isoflavones by more than three to five fold than control cells [32]. The upregulation of miR-155 has been discovered in breast cancer cell lines $[10,11]$. In prostate cancer cells, miR-155 was capable of upregulating annexin 7, which is a substrate of a variant of kinases including protein kinase $\mathrm{C}$ involved in cell growth,
A

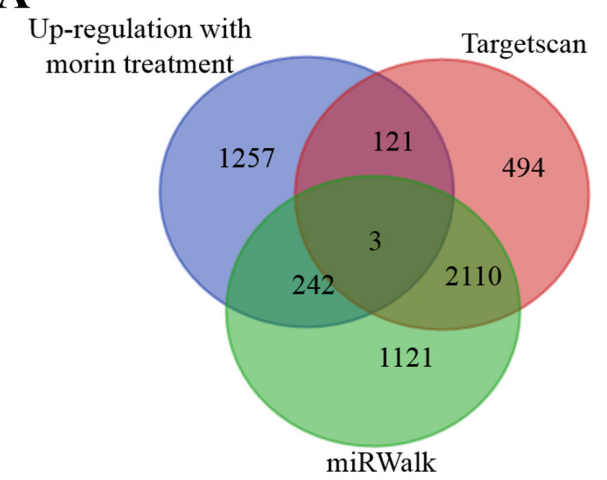

B

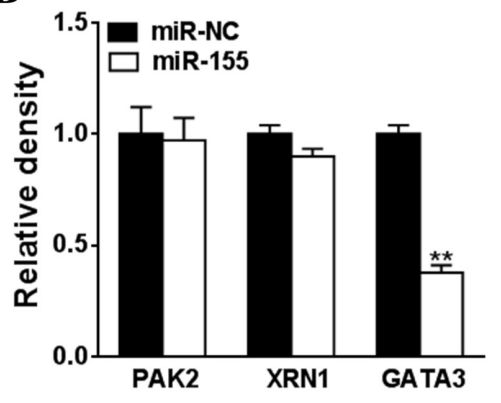

C

GATA3-WT 5'-CCACAGUUGUUUGAUGCAUUAAA-3'

|| || |

hsa-miR-155 3'-UGGGGAUAGUGCUAAUCGUAAUU-5'

GATA3-MUT 5'- CCACAGUUGUUUGAUGGAGUGAA-3'

D

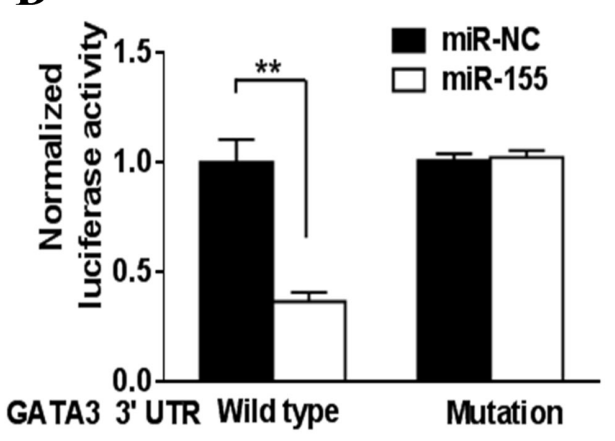

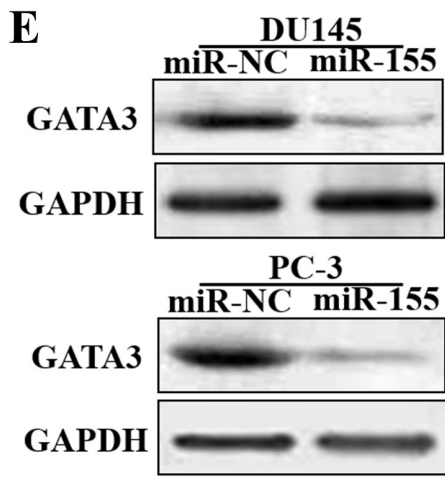

F

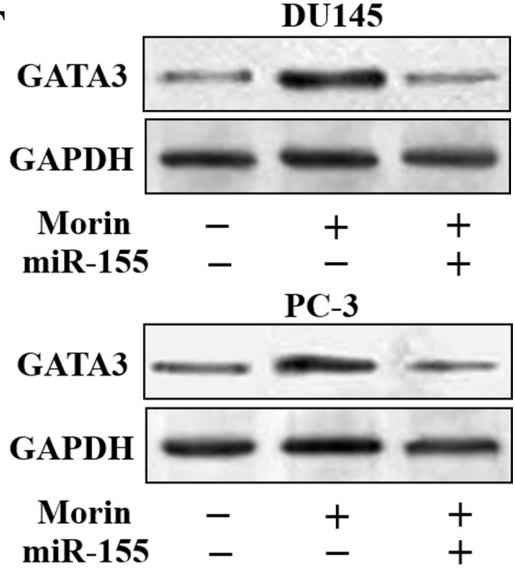

Figure 6: Morin induced miR-155 directly targets GATA3. (A) Venn diagram was used to represent the predicted targets of miR-155 in Targetscan and miRWalk which were also up-regulated with morin treatment. (B) DU145 cells were transfected with miR-155 mimics, or control miR-NC, and the relative expression levels of predicted targets were analyzed by qRT-PCR. (C) Putative seed-matching sites or mutant sites (red) between miR-155 and 3'-UTR of GATA3. (D) Luciferase reporter assay was performed on DU145 cells to detect the relative luciferase activities of WT and mut GATA3 reporters. Renilla luciferase vector was used as an internal control. Student T tests were used to verify the significance of differences between two groups. All of the experiments were triplicated and data were shown in mean \pm SD. ${ }^{* *} \mathrm{p}<0.01$. (E) DU145 or PC-3 cells were transfected with miR-155 mimics, or control miR-NC. After 48 h, total proteins of miR-155 and miR-NC-expression cells were subjected to western blotting and detected for GATA3 expression levels. GAPDH expression was served as an internal control. (F) DU145 or PC-3 cells were transfected with miR-155 mimics, or control miR-NC, and were treated with $50 \mu \mathrm{M}$ morin or DMSO. After $48 \mathrm{~h}$, total proteins of the cells were subjected to western blotting and detected for GATA3 expression levels. 
proliferation, apoptosis and migration [10]. Hence, the function of miR-155 in the development of prostate cancer might be underestimated.

The study of the targets of miR-155 in prostate cancer is still limited comparing with other cancers. For instance, in breast cancer at least 147 validated targets have been identified [33]. However, in prostate cancer, only a few downstream effectors of miR-155 have been discovered yet. In present study, we found that GATA3 can be directly regulated by miR-155. GATA3 has been shown highly expressed in normal human and mouse prostates, which is involved in the regulation of prostatespecific antigen (PSA) genes [34, 35]. However, previous researches have shown that its expression is negative in prostate cancer cell lines [34]. In Pten-deficient prostate tumors, the expression of GATA3 is gradually lost during its progression [36]. This is consistent with our results (Supplementary Figure 3). In one research 2-fold of overexpression of GATA3 was effective enough to limit the viabilities of PC-3 cells [37]. In our research we demonstrated that the treatment of morin and/or paclitaxel recovered the expression of GATA3 through inhibiting the expression of miR-155. Researches have shown that ZEB2, TGFB1, MDM2 are important downstream effectors that can be inhibited by GATA 3 in breast cancer [38]. In our study, the treatment of morin alone raised the expression of GATA3, and decreased the intracellular levels of ZEB2, TGFB1, MDM2. Therefore it is possible that there is a miR-155/GATA3 axis involved in the antitumor effects of morin as an adjuvant to paclitaxel in treating prostate cancer.

In conclusion, we hereby demonstrate that morin may improve the chemo-sensitivity of prostate cancer cells to paclitaxel through restoring the miR-155-suppressed expression of GATA3. Hence, morin may be a promising adjuvant to paclitaxel in the treatment of prostate cancer.

\section{MATERIALS AND METHODS}

\section{Cell lines}

DU145 and PC-3 prostate cancer cell lines were purchased from Xinyu Biotechnology Co. Ltd (Shanghai, China). All cell lines were cultured in RPMI 1640 (GIBCO-BRL, Grand Island, NY) medium supplemented with $10 \%$ fetal bovine serum (FBS), $100 \mathrm{U} / \mathrm{ml}$ penicillin, and $100 \mu \mathrm{g} / \mathrm{ml}$ streptomycin in humidified air at $37^{\circ} \mathrm{C}$ with $5 \% \mathrm{CO}_{2}$.

\section{Reagents}

Concentrated morin (Sigma-Aldrich, MO, USA)) or paclitaxel (Sigma-Aldrich) were dissolved in DMSO and then diluted into the cultural medium with desired concentration, in which the concentration of DMSO was less than $0.05 \%$.

\section{miRNA transfection}

MiR-155 mimics, anti-miR-155 (Anti-miR-155), miR-NC and anti-sense RNA (Anti-miR-NC) were transfected into DU145 and PC-3 cell lines through Ambion ${ }^{\circledR}$ Pre-miR ${ }^{\mathrm{TM}}$ miRNA Starter Kit (Thermo Scientific, Wilmington, DE).

\section{Cell viability assays}

Cells were seeded and cultured in 96-well plates for 24 h. Paclitaxel (Sigma Chemicals, St Louis, Mo, USA) was then added into the culture media in the gradient of $0 \mu \mathrm{M}, 3.125 \mu \mathrm{M}, 6.25 \mu \mathrm{M}, 12.5 \mu \mathrm{M}, 25 \mu \mathrm{M}, 50 \mu \mathrm{M}$, $100 \mu \mathrm{M}$. The cell viability was determined after $48 \mathrm{~h}$ of incubation using cell counting kit 8 (CCK-8) (Dojindo Laboratories, Kumamoto, Japan). In the cell viability assay, $10 \mu \mathrm{l}$ CCK-8 solution was added into each well of the plate. After $4 \mathrm{~h}$ of incubation at $37{ }^{\circ} \mathrm{C}$, the cell viabilities were analyzed at dual wave lengths $(450 \mathrm{~nm}$ and $630 \mathrm{~nm}$ ). The experiments were repeated for three times.

\section{Flow cytometry analysis of apoptosis}

Cells were cultured in $50 \mu \mathrm{M}$ morin and 50 $\mathrm{nM}$ paclitaxel for $48 \mathrm{~h}$, and then were harvested and centrifuged. The centrifuged cells were then washed twice utilizing cold PBS buffer and resuspended into the concentration of $1 \times 10^{6}$ cells $/ \mathrm{mL}$. Annexin V Apoptosis Detection kit (eBIOscience, San Diego, CA, USA) was utilized for annexin $\mathrm{V}$ double staining. Annexin $\mathrm{V}$ solution $(5 \mu \mathrm{L})$ was mixed with $100 \mu \mathrm{L}$ cell suspensions, The mixture were incubated at dark for $15 \mathrm{~min}$, and the cells were washed with $2 \mathrm{~mL} 1 \times$ binding buffer. The cells were again suspended in $200 \mu \mathrm{L}$ of $1 \times$ binding buffer 5 $\mu \mathrm{L}$ of Propidium Iodide Staining Solution was added into solution before flow cytometry. Beckman Coulter Cytomics FC 500 (San Jose, CA, USA) was employed for flow cytometry analysis.

\section{Tumor formation assay in nude mice}

$5 \times 10^{6}$ DU145 cells were centrifuged and dispersed in $100 \mu \mathrm{l}$ serum-free 1640 medium. The suspensions were injected into both sides of posterior flanks in nude mice. 50 $\mu \mathrm{g} / \mathrm{kg}$ of paclitaxel and $50 \mathrm{mg} / \mathrm{kg}$ of morin were injected through tail vein every day for 20days. Meanwhile, the tumor sizes were measured every two days since tumors can be apparently seen $\left(\right.$ Volume $=0.5 \times$ Length $\left.\times \mathrm{Width}^{2}\right)$. Tumors were excised and weighted in the $20^{\text {th }}$ day.

\section{miRNA microarray}

DU145 cells were culture in the medium containing $50 \mu \mathrm{M}$ morin or the same amount of DMSO (less than $0.05 \%$ in the medium), and after $24 \mathrm{~h}$ of incubation, the 
levels of miRNAs were checked by microarray. Total RNAs inside cells were extracted and purified through PureLinkTM Total RNA isolation Kit (Invitrogen, Carlsbed, CA, USA), and the concentration and purity of the extracted RNAs were examined with NanoDrop ND1000 spectrophotometer (Thermo Scientific). Affymetrix miRNA 4.0 Array and HG133plus2 microarrays were employed in analyzing the miRNA profiles. The signal intensity of 500 miRNA probes in both of the chips were measured, and the raw data were noemalized and analyzed using GenePix1 4000B Microarray Scanner (Thermo Scientific) and PANAGENE software (Thermo Scientific). All of the procedures were triplicated.

\section{Quantitative real time-PCR}

The total RNA of DU145 and PC-3 cell lines was reverse transcribed into first line cDNA with TaqMan Reverse Transcription Reagents (Life Technologies, Carlsbad, CA, USA), which was then subject to Bio-Rad CFX96 real-time PCR System (Bio-Rad, CA, USA). Primers were designed for different targets, and primers designed for GAPDH and U6 were applied as internal controls.:

miR-155:

Sense: 5'-AGCCTCCCGCTTCGCTCTCT-3', Antisense: 5'-AGCCTCCCGCTTCGCTCTCT-3', PAK2:

Sense: 5'-AGCCTCCCGCTTCGCTCTCT-3', Antisense: 5'-AGCCTCCCGCTTCGCTCTCT-3', XRN1:

Sense: 5'-AGCCTCCCGCTTCGCTCTCT-3', Antisense: 5'-AGCCTCCCGCTTCGCTCTCT-3', GATA3:

Sense: 5'-AGCCTCCCGCTTCGCTCTCT-3', Antisense: 5'-AGCCTCCCGCTTCGCTCTCT-3',

\section{Dual-luciferase reporter assay}

GATA3 and GATA3 MUT 3'UTR were firstly amplified using primers:

GATA3 forward: 5'-ATAGCATCGCAGGTAAC GCTACGCGGGACG-3'

GATA3 Reverse: 5'-ATAGCATCGCAGGTAAC GCTACGCGGGACG-3'

GATA3 MUT forward: 5'-ATAGCATCGCAGGT AACGCTACGCGGGACG-3'

GATA3 MUT Reverse: 5'-ATAGCATCGCAGG TAACGCTACGCGGGACG-3'

GATA3 and GATA3 mute 3' UTR were recombined upstream of Firefly luciferase in one vector (Promega, Madison, WI, USA). The luciferase reporter vectors and miR-155 mimics or miR-NC were transfected into DU145 and PC-3 cells. Renilla luciferase vector (Promega) was transfected at the same time as internal control. The luciferase activities were detected through Dual-
Glo Luciferase assay system (Promega) after $48 \mathrm{~h}$ from transfection.

\section{Western blot}

miR-155 mimics, or miR-NC control were transfected into DU145 and PC-3 cells, which were subsequently incubated with morin $(50 \mu \mathrm{M})$ and paclitaxel (0-100 nM) for $48 \mathrm{~h}$. Proteins Cell lysates of DU145/miR-155, DU145/miR-NC, PC-3/miR-155 and $\mathrm{PC}-3 / \mathrm{miR}-\mathrm{NC}$ cells treated with morin or not were then separated by SDS-PAGE. The separated proteins were then electrophoretically transferred onto NC membranes (Sigma). The membranes were blocked with 5\% non-fat milk in TBS buffer (Sigma-Aldrich,) overnight. Antihuman GATA3 primary antibody purchased from Abcam (Cambridge, MA, USA) and horseradish peroxidaseconjugated secondary antibody (Abcam) were incubated with the membrane. The antibodies were dissolved in PBS buffer and diluted in the ration of 1:1000. Enhanced Chemiluminescence (ECL) (Sigma-Aldrich) was employed to detect the immunoreactive bands through Chemigenius Bioimaging system (Syngene, Frederick MD, USA.) GADPH (Abcam) was detected as loading control.

\section{Statistical analysis}

All data was analyzed using SPSS version 13.0 (IBM, Armonk, NY, USA). The results were presented in the formation of mean \pm standard deviation (SD). One or two-way ANOVA analyses was employed for analyzing statistical differences between multiple groups. Student T tests were used to verify the significance of differences between two groups. $\mathrm{P}<0.05$ was considered as statistical significance.

\section{CONFLICTS OF INTEREST}

The authors declare that they have no conflicts of interest.

\section{FUNDING}

None.

\section{REFERENCES}

1. Weaver BA. How Taxol/paclitaxel kills cancer cells. Mol Biol Cell. 2014; 25:2677-2681.

2. Sobue S, Mizutani N, Aoyama Y, Kawamoto Y, Suzuki M, Nozawa Y, Ichihara M, Murate T. Mechanism of paclitaxel resistance in a human prostate cancer cell line, PC3-PR, and its sensitization by cabazitaxel. Biochem Biophys Res Commun. 2016; 479:808-813. 
3. Kavallaris M. Microtubules and resistance to tubulinbinding agents. Nat Rev Cancer. 2010; 10:194-204.

4. Bartel DP. MicroRNAs: genomics, biogenesis, mechanism, and function. Cell. 2004; 116:281-297.

5. Hayes J, Peruzzi PP, Lawler S. MicroRNAs in cancer: biomarkers, functions and therapy. Trends Mol Med. 2014; 20:460-469.

6. O'Connell RM, Rao DS, Chaudhuri AA, Boldin MP, Taganov KD, Nicoll J, Paquette RL, Baltimore D. Sustained expression of microRNA-155 in hematopoietic stem cells causes a myeloproliferative disorder. J Exp Med. 2008; 205:585-594.

7. O'Connell RM, Rao DS, Chaudhuri AA, Baltimore D. Physiological and pathological roles for microRNAs in the immune system. Nat Rev Immunol. 2010; 10:111-122.

8. Faraoni I, Antonetti FR, Cardone J, Bonmassar E. miR155 gene: a typical multifunctional microRNA. Biochim Biophys Acta. 2009; 1792:497-505.

9. Fu X, Wen H, Jing L, Yang Y, Wang W, Liang X, Nan K, Yao Y, Tian T. MicroRNA-155-5p promotes hepatocellular carcinoma progression by suppressing PTEN through the PI3K/Akt pathway. Cancer Sci. 2017; 108:620-631.

10. Cai ZK, Chen Q, Chen YB, Gu M, Zheng DC, Zhou J, Wang Z. microRNA-155 promotes the proliferation of prostate cancer cells by targeting annexin 7. Mol Med Rep. 2015; 11:533-538.

11. Basu S, Majumder S, Bhowal A, Ghosh A, Naskar S, Nandy S, Mukherjee S, Sinha RK, Basu K, Karmakar D, Banerjee S, Sengupta S. A study of molecular signals deregulating mismatch repair genes in prostate cancer compared to benign prostatic hyperplasia. PLoS One. 2015; 10:e0125560.

12. Zhang C, Zhao J, Deng H. 17beta-estradiol up-regulates miR-155 expression and reduces TP53INP1 expression in MCF-7 breast cancer cells. Mol Cell Biochem. 2013; 379:201-211.

13. Huang X, Shen Y, Liu M, Bi C, Jiang C, Iqbal J, McKeithan TW, Chan WC, Ding SJ, Fu K. Quantitative proteomics reveals that miR-155 regulates the PI3K-AKT pathway in diffuse large B-cell lymphoma. Am J Pathol. 2012; 181:26-33.

14. Kong W, He L, Richards EJ, Challa S, Xu CX, PermuthWey J, Lancaster JM, Coppola D, Sellers TA, Djeu JY, Cheng JQ. Upregulation of miRNA-155 promotes tumour angiogenesis by targeting VHL and is associated with poor prognosis and triple-negative breast cancer. Oncogene. 2014; 33:679-689.

15. Jin H, Lee WS, Eun SY, Jung JH, Park HS, Kim G, Choi YH, Ryu CH, Jung JM, Hong SC, Shin SC, Kim HJ. Morin, a flavonoid from Moraceae, suppresses growth and invasion of the highly metastatic breast cancer cell line MDA-MB231 partly through suppression of the Akt pathway. Int J Oncol. 2014; 45:1629-1637.
16. Batra P, Sharma AK. Anti-cancer potential of flavonoids: recent trends and future perspectives. 3 Biotech. 2013; $3: 439-459$.

17. Gupta SC, Phromnoi K, Aggarwal BB. Morin inhibits STAT3 tyrosine 705 phosphorylation in tumor cells through activation of protein tyrosine phosphatase SHP1. Biochem Pharmacol. 2013; 85:898-912.

18. Park C, Lee WS, Go SI, Nagappan A, Han MH, Hong SH, Kim GS, Kim GY, Kwon TK, Ryu CH, Shin SC, Choi YH. Morin, a flavonoid from moraceae, induces apoptosis by induction of BAD protein in human leukemic cells. Int $\mathrm{J}$ Mol Sci. 2014; 16:645-659.

19. Caselli A, Cirri P, Santi A, Paoli P. Morin: a promising natural drug. Curr Med Chem. 2016; 23:774-791.

20. Bracarda S, Logothetis C, Sternberg CN, Oudard S. Current and emerging treatment modalities for metastatic castrationresistant prostate cancer. BJU Int. 2011; 107:13-20.

21. Madan RA, Pal SK, Sartor O, Dahut WL. Overcoming chemotherapy resistance in prostate cancer. Clin Cancer Res. 2011; 17:3892-3902.

22. Petrylak DP, Tangen CM, Hussain MH, Lara PN Jr, Jones JA, Taplin ME, Burch PA, Berry D, Moinpour C, Kohli M, Benson MC, Small EJ, Raghavan D, et al. Docetaxel and estramustine compared with mitoxantrone and prednisone for advanced refractory prostate cancer. N Engl J Med. 2004; 351:1513-1520.

23. Tannock IF, de Wit R, Berry WR, Horti J, Pluzanska A, Chi KN, Oudard S, Theodore C, James ND, Turesson I, Rosenthal MA, Eisenberger MA. Docetaxel plus prednisone or mitoxantrone plus prednisone for advanced prostate cancer. N Engl J Med. 2004; 351:1502-1512.

24. Kim JJ, Yin B, Christudass CS, Terada N, Rajagopalan K, Fabry B, Lee DY, Shiraishi T, Getzenberg RH, Veltri RW, An SS, Mooney SM. Acquisition of paclitaxel resistance is associated with a more aggressive and invasive phenotype in prostate cancer. J Cell Biochem. 2013; 114:1286-1293.

25. Liu W, Guo R. Effects of Triton X-100 nanoaggregates on dimerization and antioxidant activity of morin. Mol Pharm. 2008; 5:588-597.

26. Kuo HM, Chang LS, Lin YL, Lu HF, Yang JS, Lee JH, Chung JG. Morin inhibits the growth of human leukemia HL-60 cells via cell cycle arrest and induction of apoptosis through mitochondria dependent pathway. Anticancer Res. 2007; 27:395-405.

27. Brown J, O'Prey J, Harrison PR. Enhanced sensitivity of human oral tumours to the flavonol, morin, during cancer progression: involvement of the Akt and stress kinase pathways. Carcinogenesis. 2003; 24:171-177.

28. Zhang S, Yang X, Morris ME. Flavonoids are inhibitors of breast cancer resistance protein (ABCG2)-mediated transport. Mol Pharmacol. 2004; 65:1208-1216.

29. Romero I, Paez A, Ferruelo A, Lujan M, Berenguer A. Polyphenols in red wine inhibit the proliferation and induce apoptosis of LNCaP cells. BJU Int. 2002; 89:950-954. 
30. Ferruelo A, Romero I, Cabrera PM, Arance I, Andres G, Angulo JC. Effects of resveratrol and other wine polyphenols on the proliferation, apoptosis and androgen receptor expression in LNCaP cells. Actas Urol Esp. 2014; 38:397-404.

31. Walter BA, Valera VA, Pinto PA, Merino MJ. Comprehensive microRNA profiling of prostate cancer. $\mathrm{J}$ Cancer. 2013; 4:350-357.

32. Rabiau N, Trraf HK, Adjakly M, Bosviel R, Guy L, Fontana L, Bignon YJ, Bernard-Gallon DJ. miRNAs differentially expressed in prostate cancer cell lines after soy treatment. In Vivo. 2011; 25:917-921.

33. Mattiske S, Suetani RJ, Neilsen PM, Callen DF. The oncogenic role of miR-155 in breast cancer. Cancer Epidemiol Biomarkers Prev. 2012; 21:1236-1243.

34. Jain RK, Mehta RJ, Nakshatri H, Idrees MT, Badve SS. High-level expression of forkhead-box protein A1 in metastatic prostate cancer. Histopathology. 2011; 58:766-772.
35. Lakshmanan G, Lieuw KH, Lim KC, Gu Y, Grosveld F, Engel JD, Karis A. Localization of distant urogenital system-, central nervous system-, and endocardium-specific transcriptional regulatory elements in the GATA-3 locus. Mol Cell Biol. 1999; 19:1558-1568.

36. Nguyen AH, Tremblay M, Haigh K, Koumakpayi IH, Paquet M, Pandolfi PP, Mes-Masson AM, Saad F, Haigh JJ, Bouchard M. Gata3 antagonizes cancer progression in Ptendeficient prostates. Hum Mol Genet. 2013; 22:2400-2410.

37. Jiang X, Chen Y, Du E, Yang K, Zhang Z, Qi S, Xu Y. GATA3-driven expression of miR-503 inhibits prostate cancer progression by repressing ZNF217 expression. Cell Signal. 2016; 28:1216-1224.

38. Si W, Huang W, Zheng Y, Yang Y, Liu X, Shan L, Zhou X, Wang Y, Su D, Gao J, Yan R, Han X, Li W, et al. Dysfunction of the reciprocal feedback loop between GATA3- and ZEB2-nucleated repression programs contributes to breast cancer metastasis. Cancer Cell. 2015; 27:822-836. 